\title{
Applicability of UH model to coarse-grained soil
}

\author{
Xiaolong Zhao ${ }^{1,2}$, Jungao Zhu ${ }^{1, *}$, Hanbing Bian ${ }^{3}$ \\ ${ }^{1}$ Key Laboratory of Ministry of Education for Geomechanics and Embankment Engineering, Hohai \\ University, 210098 Nanjing, China \\ ${ }^{2}$ Laboratoire de Mécanique, Multiphysique, Multiéchelle, Université de Lille, 5900 Lille, France \\ ${ }^{3}$ Laboratoire de Génie Civil et géo-Environnement, Université de Lille, 5900 Lille, France
}

\begin{abstract}
Large-scale triaxial, K0 compression and constant stress ratio path tests were carried out on two kinds of coarse-grained soils. Stress-strain relationships of these tests were simulated by using UH model for sands to study the applicability of the model to different stress paths of coarsegrained soil, and the results were compared with those of Duncan's E-B model. It is shown that the mechanical behaviors of coarse-grained soil can be well described by the UH model, and overall its capacity to reflect stressstrain relationship under different stress paths is better than that of Duncan's E-B model. Finally, the UH model and Duncan's E-B model were used for stress-deformation analysis of a core rockfill dam. The applicability of UH model for sands to coarse-grained soil was verified.
\end{abstract}

\section{Introduction}

With the challenges of climate change and for reducing the emission of greenhouse gas, the renewable energy, such as the hydropower, has been rapidly developed in China [1]. Numerous high earth rockfill dams have been or under constructions in western China. The safety of the hydraulic centre, as well as the dams, the residents and the infrastructures in the downstream area is of major concerns for the hydropower exploitation. A good understanding of the mechanical and/or hydro-mechanical behaviour of the dam is necessary. In fact, for the rockfill dams, the most volumetric part is composed of the so-called rockfill, with an average diameter larger than that we frequently encountered in the laboratories. The classic laboratory test equipment is not suitable for this type of soil. So, the rockfill material is usually scaled into smaller sized material called coarse-grained soil for laboratory test. To avoid the error caused by laboratory test, some in-situ measurements are also developed, but the in-situ measurements have also some difficulties [2-3]. Nowadays, the model parameters used for analysis are still mainly gained by laboratory test [4]. In this context, a series of research on the coarse-grained soil was carried out, with the laboratory test and the numerical approaches. Based on special laboratory tests, a constitutive model has been verified for this type of soil, and then the model has been applied to a rockfill dam. The current article is organised as following, after a short introduction, the model is briefly introduced, then the

\footnotetext{
Corresponding author: zhujungao@hhu.edu.cn
} 
experimental research is presented, an application on a rockfill dam is given for the illustration. The discussions and conclusions are given at the end.

At present, many soil constitutive models have been put forward, including nonlinear elastic models [5-8] and elastoplastic models [9-13]. However, most of the models were proposed for clay or sand, and few constitutive models for coarse-grained soil.

Yao et al. [14-15] proposed the three-dimensional unified hardening model for overconsolidated clays (the UH model), based on the relationship between the current yield surface and reference yield surface. The UH model can model many characteristics of overconsolidated clays well, including stress-strain relationships, shear dilatancy, strainhardening and softening, and stress path dependence behaviour.

In order to describe the similarities and differences between clays and sands in a unified constitutive model, Yao et al. [16] developed the UH model for clays and sands, called UH model for sands.

\section{UH model for sands}

The UH model for sands, developed by Yao et al. [16], is a constitutive model based on the unified hardening (UH) model [15].

\subsection{Shear yielding of sands and its description}

A new parameter is introduced into the yield function of the modified Cam-clay model, and is expressed as

$$
f=\frac{(1+\chi) q^{2}}{M^{2} p^{2}-\chi q^{2}}+1-\frac{p_{x}}{p}=0
$$

where $\chi$ is defined as the critical state parameter since it can adjust the vertical distance between NCL and CSL, and it is non-negative and smaller than $1 ; M$ is critical state stress ratio; $p$ is mean effective stress, $\mathrm{kPa} ; q$ is deviatoric stress, $\mathrm{kPa}$; and $p_{\mathrm{x}}$ is intersection of the current yield surface with the $p$-axis, $\mathrm{kPa}$.

\subsection{Dilatancy of sands and its description}

The state when the plastic deformation turns from contraction to dilatancy, is a characteristic state used to describe the dilatancy of sands. Here, the equation of the phase transformation line is adopted as that of the characteristic state stress ratio $M_{\mathrm{c}}$.

$$
M_{c}=M \cdot \exp (-m \cdot \xi)
$$

where $m$ is a dilatancy parameter; $\xi$ is state variable describing the current density.

\section{The large-scale triaxial test and KO test}

\subsection{Test material and test method}

Soils used for tests are one sandy pebble and one gravel. The sandy pebble (denoted by LS) was taken from Dashixia Concrete Faced Sand-gravel Dam, China, while the gravel (denoted by SS) was taken from Maji Rockfill Dam, China. Grain gradations of the two soils are shown in Table 1. 
Table 1 Particle size distribution of soil samples

\begin{tabular}{ccccccc}
\hline \multirow{2}{*}{ Material } & \multirow{6}{*}{ No. Mass percentage (\%) of particle groups } \\
\cline { 3 - 7 } & & $60 \sim 40$ & $40 \sim 20$ & $20 \sim 10$ & $10 \sim 5$ & $<5$ \\
\hline Sandy & LS & 17.6 & 23.8 & 18.4 & 11.7 & 28.5 \\
pebble & & & & \\
Gravel & SS & 16.9 & 22.9 & 19.6 & 16.1 & 24.5 \\
\hline
\end{tabular}

Large-scale consolidated-drained (CD) triaxial tests were conducted on soils of LS and SS with specimen densities 2.04 and $2.20 \mathrm{~g} / \mathrm{cm}^{3}$. The void ratios of LS and of SS are 0.34 and 0.23 . The specimen size is $300 \mathrm{~mm}$ in diameter and $600 \mathrm{~mm}$ in height, and the confining pressures in tests for LS are $600,1200,1800$ and $2400 \mathrm{kPa}$, and those for SS are 400, 800, 1600 and $2400 \mathrm{kPa}$, respectively. The tests were conducted by a large-scale triaxial apparatus, which was in the key laboratory of ministry of education for geomechanics and embankment engineering, Hohai University (Fig. 1(a)). Besides, the constant stress ratio path tests were also carried out by this apparatus, and the stress ratio $\left(\sigma_{1} / \sigma_{3}\right)$ was kept to 2.5 during loading.

In the CD triaxial test, a negative pressure was maintained in the samples for 15 mins before saturation. Then the samples were saturated by allowing water to pass through the base of the triaxial cell and using a top drainage system for removing air voids. The samples were first subjected to the required consolidation pressure and were then sheared by applying axial loading to achieve a rate of loading of $1 \mathrm{~mm} / \mathrm{min}$. The shear procedure was terminated when the axial strain reached $15 \%$. In the constant stress ratio path test, the only difference between the $\mathrm{CD}$ test is that the $\sigma_{1} / \sigma_{3}$ was kept to 2.5 during shearing. The rate of loading was $1 \mathrm{~mm} / \mathrm{min}$, and the initial confining pressure $\sigma_{3}$ was $30 \mathrm{kPa}$ in consolidation phase, which would rise with the increase of in shearing.

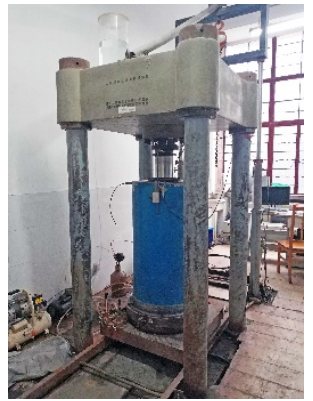

(a) Large-scale triaxial apparatus

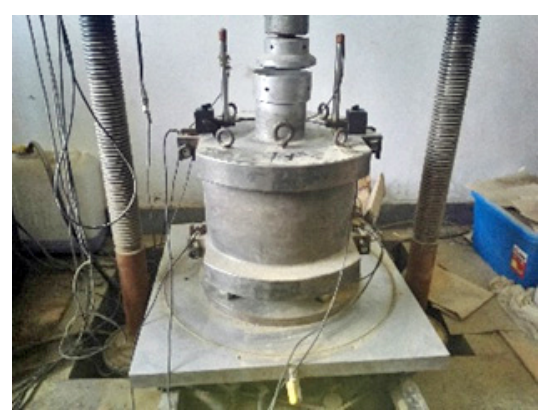

(b) Large-scale K0 apparatus

Fig. 1. Apparatus for laboratory tests

$\mathrm{K} 0$ compression tests were performed on LS soil. The apparatus is a large sized oedometer, newly developed by Hohai University [17] (Fig. 1(b)). The maximum axial force can be 800 $\mathrm{kN}$, with an axial stress up to $6.4 \mathrm{MPa}$. The soil sample was dry, with $400 \mathrm{~mm}$ in diameter and $300 \mathrm{~mm}$ in height. Stress control was adopted during the test, with a rate of loading of $10 \mathrm{kPa} / \mathrm{min}$.

\subsection{Analysis of laboratory test results}

Triaxial test results are shown as scattered points in Fig. 2. The test results were also predicted by UH model for sands (hereinafter called UH model) and Duncan's E-B model (hereinafter called E-B model) with parameters given in Table 2 and 3, which are shown with dashed and solid lines, respectively. 
Table 2 Parameters of Duncan's E-B model

\begin{tabular}{cccccccc}
\hline Material & $R_{f}$ & $K$ & $n$ & $K_{b}$ & $m$ & $\varphi_{0} /\left(^{\circ}\right)$ & $\Delta \varphi /\left(^{\circ}\right)$ \\
\hline LS & 0.77 & 530 & 0.56 & 364 & 0.16 & 52.27 & 6.77 \\
SS & 0.73 & 1361 & 0.36 & 527 & 0.29 & 55.48 & 9.55 \\
\hline
\end{tabular}

Table 3 Parameters of UH model

\begin{tabular}{ccccccccc}
\hline Material & $M$ & $v$ & $\kappa$ & $\lambda$ & $N$ & $Z$ & $\chi$ & $m$ \\
\hline LS & 1.92 & 0.21 & 0.07 & 0.15 & 1.86 & 0.57 & 0.87 & 0.1 \\
SS & 1.69 & 0.18 & 0.04 & 0.07 & 0.95 & 0.39 & 0.72 & 0.1 \\
\hline
\end{tabular}

Fig. 2(a) shows that LS presents strain hardening and shear contraction. There is a good agreement between the model simulations and test results for the two models. Fig. 2(b) shows that SS is strain softening and shear dilatancy. The UH model is obviously superior to E-B model.

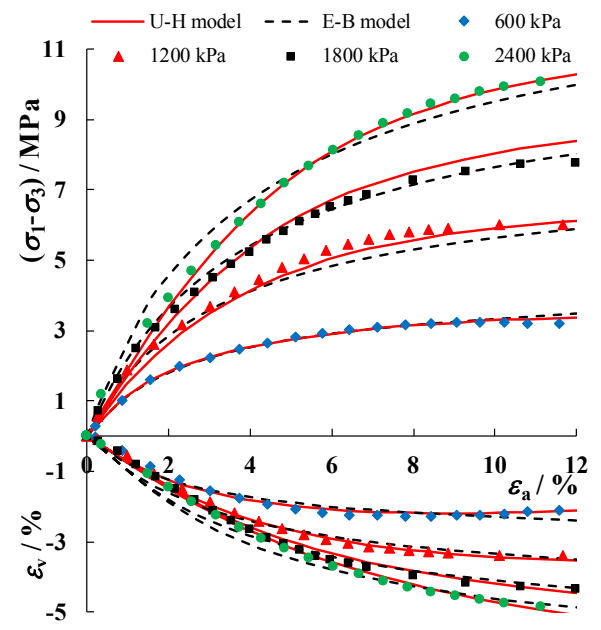

(a) LS

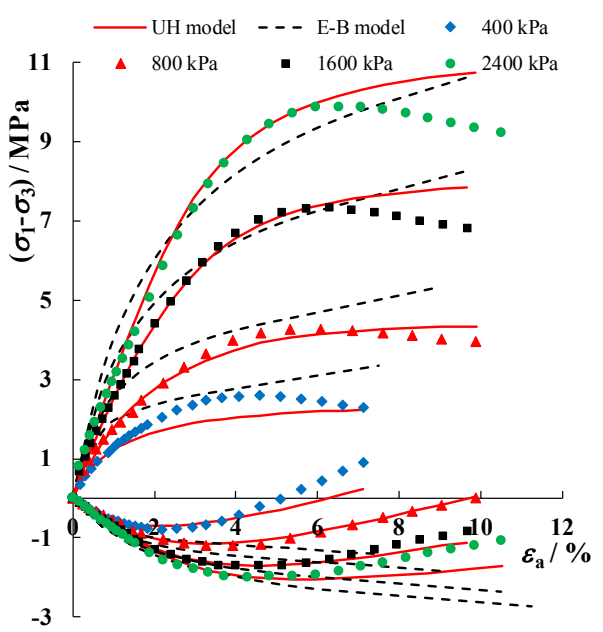

(b) SS

Fig. 2. Comparison between triaxial $\mathrm{CD}$ test results and model predictions

Fig. 3 shows the predictions of K0 compression test results on LS by the two models. The model parameters used are the same as the triaxial test, given in Table 2 and 3. Apparently, the predictions of $\mathrm{UH}$ model is closer to the test data than that of E-B model,

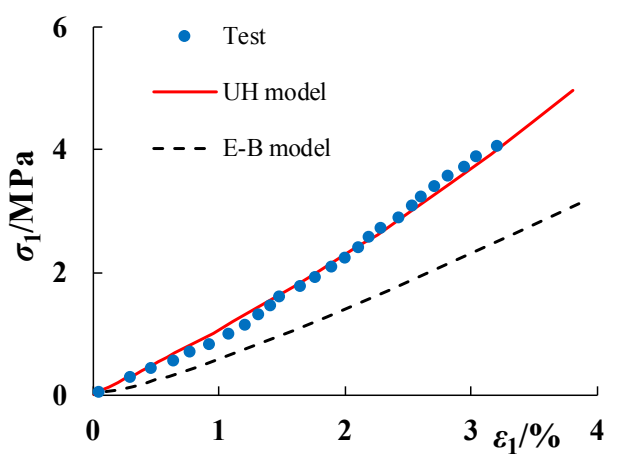

(a) Relationship between $\sigma_{1}$ and $\varepsilon_{1}$

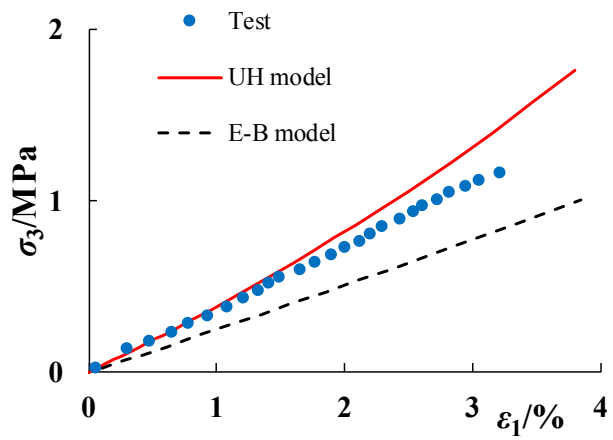

(b) Relationship between $\sigma_{3}$ and $\varepsilon_{1}$

Fig. 3. Comparison between $\mathrm{K} 0$ compression test results and model predictions on LS sample 
Fig. 4 gives the predictions of the constant stress ratio path test results on SS, with the same model parameters (given in Table 2 and 3). The predictions of UH model agrees well with the test results, and there is an evident deviation between the prediction of E-B model and test data for the $p-\varepsilon_{\mathrm{V}}$ relationship. For the $q-\varepsilon_{\mathrm{a}}$ relationship, both the two models cannot well predict the test results, but the predictions of $\mathrm{UH}$ model is still better.

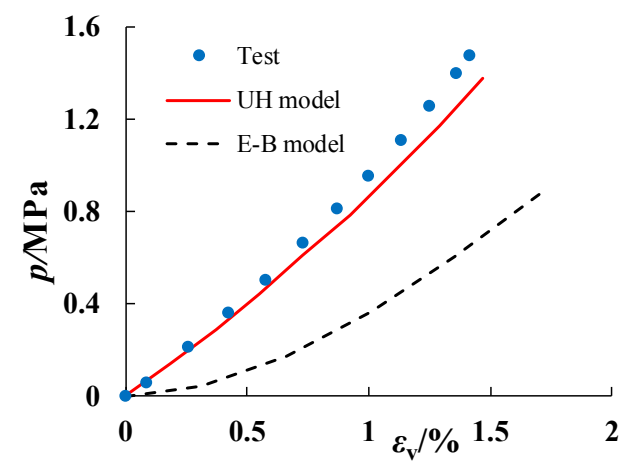

(a) Relationship between $p$ and $\varepsilon_{\mathrm{v}}$

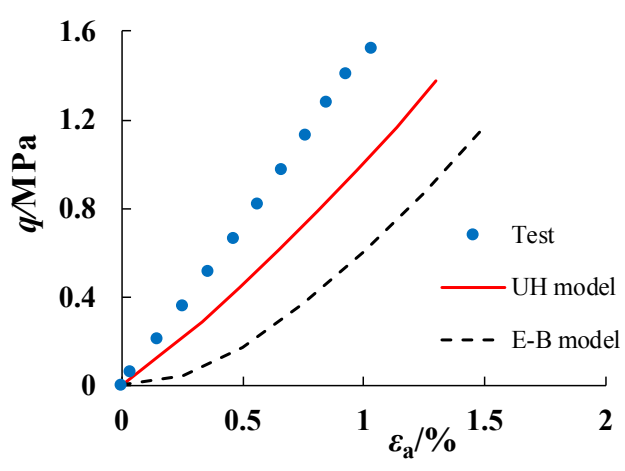

(b) Relationship between $q$ and $\varepsilon_{\mathrm{a}}$

Fig. 4. Comparison between constant stress ratio test results and model predictions on SS sample

\section{Application of stress-deformation analysis in Rockfill dam}

In this section, the stress-deformation analysis of a core rockfill dam was performed by UH model and E-B model, the calculation results were then compared.

\subsection{Overview of the dam and finite element model}

The earth rockfill dam is $240 \mathrm{~m}$ high and the main material zones of the dam are rockfill, transition layer, inverted filter, clay core, ground soil, etc (Fig. 5).

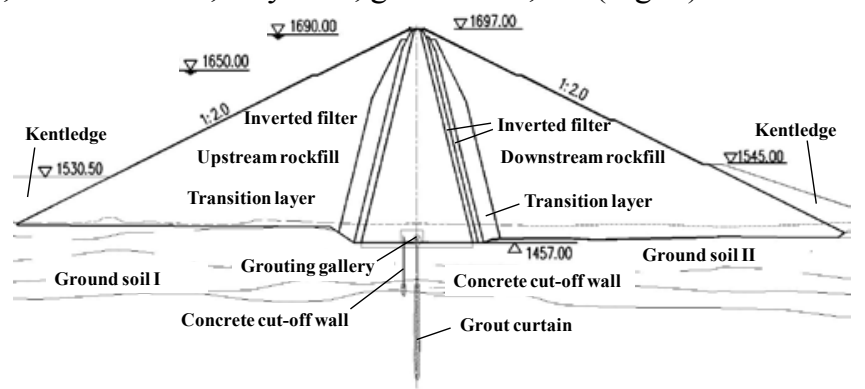

Fig. 5. Typical cross section of core rockfill dam

The model parameters for UH model and E-B model are listed in Table 4 and 5, which were determined with laboratory triaxial test. The concrete material part, such as cut-off wall, was assumed to be linear elastic, with elastic modulus $E=30 \mathrm{GPa}$ and Poisson ratio $v=0.17$. 
Table 4 Parameters of Duncan's E-B model

\begin{tabular}{cccccccccc}
\hline Material & $\begin{array}{c}\rho \\
/\left(\mathrm{g} \cdot \mathrm{cm}^{-3}\right)\end{array}$ & $\begin{array}{c}\varphi_{0} \\
/\left(^{\circ}\right)\end{array}$ & $\begin{array}{c}\Delta \varphi \\
/\left(^{\circ}\right)\end{array}$ & $\begin{array}{c}c \\
/ \mathrm{kPa}\end{array}$ & $R_{\mathrm{f}}$ & $K$ & $n$ & $K_{\mathrm{b}}$ & $m$ \\
\hline Rockfill & 2.18 & 52.9 & 8.6 & 0 & 0.83 & 1155 & 0.49 & 456 & 0.25 \\
Transition layer & 2.25 & 52.2 & 7.3 & 0 & 0.81 & 1017 & 0.32 & 353 & 0.21 \\
Inverted filter & 2.17 & 51.2 & 7.8 & 0 & 0.74 & 1363 & 0.27 & 460 & 0.19 \\
Clay core & 2.21 & 30.4 & 0 & 96 & 0.79 & 402 & 0.44 & 204 & 0.42 \\
Ground soil I & 1.45 & 48.0 & 7 & 0 & 0.80 & 1100 & 0.34 & 360 & 0.32 \\
Ground soil II & 1.31 & 46.9 & 6.5 & 0 & 0.77 & 1075 & 0.33 & 343 & 0.27 \\
\hline
\end{tabular}

Table 5 Parameters of UH model

\begin{tabular}{ccccccccc}
\hline Material & $M$ & $v$ & $\kappa$ & $\lambda$ & $N$ & $Z$ & $\chi$ & $m$ \\
\hline Rockfill & 1.700 & 0.11 & 0.05 & 0.169 & 1.887 & 0.567 & 0.28 & 0.25 \\
$\begin{array}{c}\text { Transition } \\
\text { layer }\end{array}$ & 1.699 & 0.20 & 0.05 & 0.192 & 1.900 & 0.272 & 0.43 & 1.37 \\
$\begin{array}{c}\text { Inverted } \\
\text { filter }\end{array}$ & 1.700 & 0.19 & 0.02 & 0.100 & 1.155 & 0.462 & 0.23 & 0.11 \\
Clay core & 1.487 & 0.40 & 0.01 & 0.100 & 1.170 & 0.593 & 0.44 & 0.55 \\
\hline
\end{tabular}

There are 17780 nodes and 19363 elements in the finite element model. Most of the elements are 8-node hexahedrons, with a few others, such as 6-node pentahedrons and 4node tetrahedrons for transition. Fig. 6 shows the three-dimensional finite element mesh of the dam.

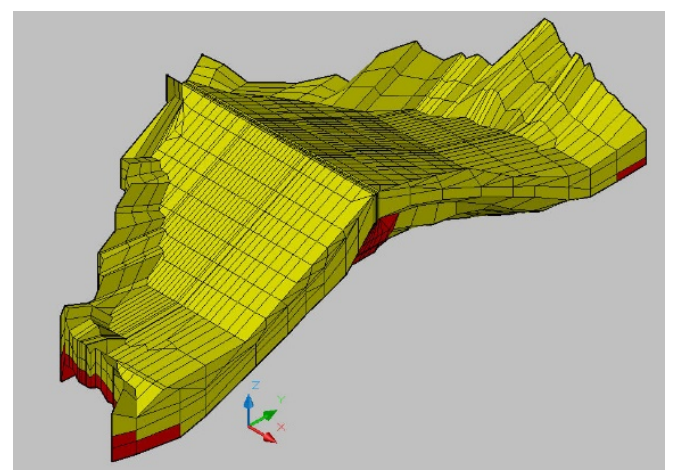

Fig. 6. Three-dimensional finite element mesh of dam body

\subsection{Calculation results comparison between models}

The settlement of rockfill dam is usually about $1 \% \sim 2 \%$ of the dam height, and displacement ratio (maximum horizontal displacement along river to maximum settlement) is less than 0.25 [18]. In this paper, the settlement from E-B model accounts for $1.3 \%$ of the dam height (including the ground soil, $50 \mathrm{~m}$ ), with the displacement ratio 0.18 , while the settlement ratio from $\mathrm{UH}$ model is $0.9 \%$, with the displacement ratio 0.19 , which are all within the reasonable range. 
Fig. 7 shows the contour lines of major principal stress in the maximum cross section. Due to the so-called arch effect, the major principal stress in core wall is smaller than that in transition layer at the same elevation. The arch effect calculated by E-B model is stronger than that by UH model.

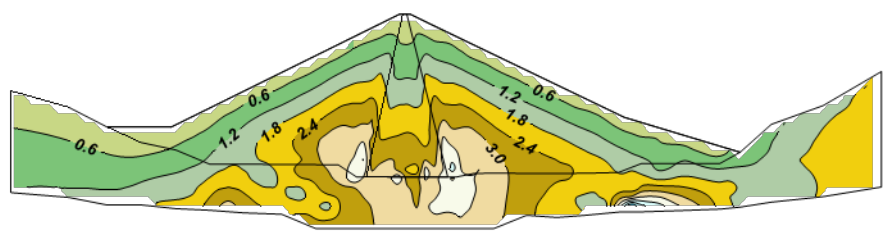

(a) E-B model

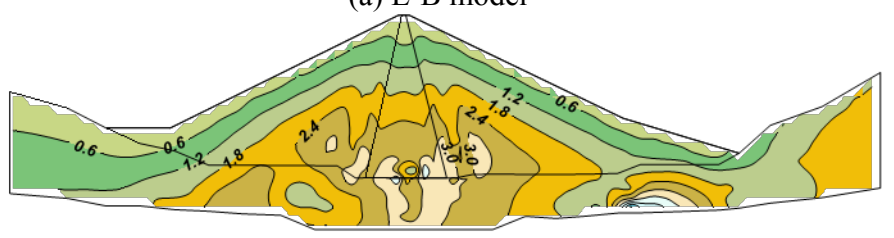

(b) UH model

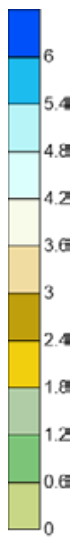

Fig. 7. Contour lines of major principal stress at completion (unit: $\mathrm{MPa}$ )

\section{Discussion and Conclusions}

In this paper, large-scale triaxial test and $\mathrm{K} 0$ compression test were conducted on two coarsegrained soils. The test results were predicted by UH model and by E-B model. By comparison, the UH model was better than E-B model in the prediction of these test data. Furthermore, the UH model can be well applied in the stress-deformation analysis of rockfill dam, as shown in section 4. The following conclusions are drawn:

(1) The stress-strain relationship of triaxial CD test can be relatively well described by both UH model and E-B model. However, for the coarse-grained soil with strain softening and shear dilatancy, E-B model has a poor ability of simulation, and it cannot reflect these behaviours while UH model can describe these properly.

(2) Simulations of K0 compression test and constant stress ratio test show that UH model can well predict stress-strain relations under complex stress paths, and the predictions are better than that of E-B model.

(3) Finite element analysis indicates that UH model can be applied in the calculation of earth rockfill dam.

\section{Acknowledgements}

The authors gratefully acknowledge the financial support from the National Key Research and Development Program of China (Grant No. 2017YFC0404801), the National Natural Science Foundation of China (Grant No. 51479052) and the Chinese Scholarship Council.

\section{References}

1. Z.Z. Yin. Stress and deformation of high earth and rock-fill dams. Chinese Journal of Geotechnical Engineering, 31 (1), 1-14 (2009) (in Chinese).

2. W.J. Xu, Q. Xu, R.L. Hu. Study on the shear strength of soil-rock mixture by large 
scale direct shear test. International Journal of Rock Mechanics and Mining Sciences, 48 (8), 1235-1247 (2011).

3. M. Sanei, L. Faramarzi, A. Fahimifar, S. Goli, A. Mehinrad, A. Rahmati. Shear strength of discontinuities in sedimentary rock masses based on direct shear tests. International Journal of Rock Mechanics and Mining Sciences, 75, 119-131 (2015).

4. G.X. Li. Some problems in researches on constitutive model of soil. Chinese Journal of Geotechnical Engineering, 31 (10): 1636-1641 (2009) (in Chinese).

5. T.L. Konder. Hyperbolic stress-strain response: cohesive soils. Journal of Soil Mechanics and Foundation, 89 (1), 115-143 (1963) (ASCE).

6. J.M. Duncan, C.Y. Chang. Nonlinear Analysis of stress and strain in soils. Journal of the Geotechnical Engineering Division, 96 (5), 1629-1653 (1970) (ASCE).

7. J.M. Duncan, P. Byrne, K.S. Wong, P. Mabry. Strength, stress-strain and bulk modulus parameters for finite element analysis of stress and movement in soil masses. Berkeley: University of California (1980).

8. Z.L. Cheng, J.S. Jiang, H.S. Ding, Y.Z. Zuo. Nonlinear dilatancy model for coarsegrained soils. Chinese Journal of Geotechnical Engineering, 32 (3), 460-467 (2010) (in Chinese).

9. K.H. Roscoe, A.N. Schofield, A. Thurairajah. Yielding of clays in states wetter than critical. Geotechnique, 8 (2), 22-53 (1963).

10. K.H. Roscoe, J.B. Burland. On the generalized stress-strain behaviour of wet clay. Cambridge University Press, Cambridge, 535-609 (1968).

11. P.V. Lade, J.M. Duncan. Elastoplastic stress-strain theory for cohesionless soil. Journal of the Geotechnical Engineering Division, 101 (10), 1037-1053 (1975).

12. K.M. Wei, S.S. Chen, G.Y. Li, Z.Z. Fu. Constitutive model for coarse-grained dam materials considering state parameter. Chinese Journal of Geotechnical Engineering, 38 (4), 654-661 (2016) (in Chinese).

13. S.H. Bian, G.Y. Li, K.M. Wei, J. Zhou. Modified generalized plasticity model for rockfill materials. Chinese Journal of Geotechnical Engineering, 39 (10), 1936-1942 (2017) (in Chinese).

14. Y.P. Yao, W. Hou, A.N. Zhou. Constitutive model for overconsolidated clays. Science in China Series E: Technological Sciences, 51 (2), 179-191 (2008).

15. Y.P. Yao, W. Hou, A.N. Zhou. UH model: three-dimensional unified hardening model for overconsolidated clays. Geotechnique, 59 (5), 451-469 (2009).

16. Y.P. Yao, L. Liu, T. Luo, Y. Tian, J. M. Zhang. Unified hardening (UH) model for clays and sands. Computers and Geotechnics, 110, 326-343 (2019).

17. J.G. Zhu, M.J. Jiang, Y.Y. Lu, W.L. Guo, B. Zhang. Experimental study on the $K_{0}$ coefficient of sandy gravel under different loading conditions. Granular Matter, 20 (3), 1-9 (2018).

18. X.L. Zhao, J. G. Zhu, P. Wang. A comparison of two constitutive models in stress and deformation analysis of earth rockfill dams. China Rural Water and Hydropower, 1, 165-169, 173 (2018) (in Chinese). 